\title{
Interaction of surface-modified silica nanoparticles with clay minerals
}

\author{
Cigdem Omurlu' ${ }^{1}$ H. Pham $^{2} \cdot$ Q. P. Nguyen ${ }^{2}$
}

Received: 12 February 2016/Accepted: 5 May 2016/Published online: 26 May 2016

(c) The Author(s) 2016. This article is published with open access at Springerlink.com

\begin{abstract}
In this study, the adsorption of 5-nm silica nanoparticles onto montmorillonite and illite is investigated. The effect of surface functionalization was evaluated for four different surfaces: unmodified, surfacemodified with anionic (sulfonate), cationic (quaternary ammonium (quat)), and nonionic (polyethylene glycol (PEG)) surfactant. We employed ultraviolet-visible spectroscopy to determine the concentration of adsorbed nanoparticles in conditions that are likely to be found in subsurface reservoir environments. PEG-coated and quat/ PEG-coated silica nanoparticles were found to significantly adsorb onto the clay surfaces, and the effects of electrolyte type $(\mathrm{NaCl}, \mathrm{KCl})$ and concentration, nanoparticle concentration, $\mathrm{pH}$, temperature, and clay type on PEG-coated nanoparticle adsorption were studied. The type and concentration of electrolytes were found to influence the degree of adsorption, suggesting a relationship between the interlayer spacing of the clay and the adsorption ability of the nanoparticles. Under the experimental conditions reported in this paper, the isotherms for nanoparticle adsorption onto montmorillonite at $25{ }^{\circ} \mathrm{C}$ indicate that adsorption occurs less readily as the nanoparticle concentration increases.
\end{abstract}

Keywords Silica nanoparticles · Montmorillonite · Adsorption isotherms · Polyethylene glycol - Sulfonate . Quaternary ammonium

Cigdem Omurlu

Cigdem@utexas.edu

1 Shell Exploration \& Production Co., 701 Poydras St., New Orleans, 70139, LA, USA

2 Department of Petroleum and Geosystems Engineering, The University of Texas at Austin, Austin, TX, USA

\section{Introduction}

Nanoparticles have recently gained attention in the oil and gas industry for their potential application in enhanced oil recovery (EOR) and as nanosensors in hydrocarbon reservoirs (Amanullah and Al-Tahini 2009; Krishnamoorti 2006; Mokhatab et al.2006; Sensoy et al. 2009). In addition to their increased surface area, the ability to functionalize nanoparticles through surface modifications make them attractive agents in the oil industry (El-Diasty and Ragab 2013) as well as many other fields. A main topic of research is the application of nanoparticles as drilling fluid additives or "smart fluids" that can be tailored for specific industrial applications (Amanullah and Al-Tahini 2009; Cai et al. 2011). Sensoy et al. (2009) reported that nanoparticles at $10 \mathrm{wt} \%$ or higher concentrations could plug shale pore throats and reduce permeability to minimize fluid invasion. Cai et al. (2011) argued that the use of nanoparticles in drilling fluids would be the first large-scale application of nanotechnology in the oil and gas industry. The authors showed experimentally that unmodified nanoparticles could reduce the invasion of water-based drilling fluids into shale.

Successful application is dependent upon understanding the transport of nanoparticles in wellbores and hydrocarbon formations. The mobility, retention, and transport fate of nanoparticles in natural formations are greatly influenced not only by characteristics of the nanoparticle itself, such as concentration and surface modifications, but also by subsurface environmental conditions, such as the electrolyte type and concentration, temperature, and the $\mathrm{pH}$ and mineral composition of the formation.

Characterizing the retention of nanoparticles onto clay minerals due to adsorption under subsurface conditions is necessary for selecting the types of nanoparticles or surface 
modification to be used as suitable nanosensors or EOR agents. Most hydrocarbon reservoir rocks contain clay minerals. Kaolinite, montmorillonite, illite, and chlorite are abundant in sandstone. The basic structure of clay minerals consists of a sheet of oxygen or hydroxyl groups embedding heavy metals, such as aluminum, iron, or magnesium atoms, and a sheet of silica tetrahedral. Two sheets of silica sandwiching on one sheet of aluminum define a basic layer of montmorillonite. These layers are separated by thin aqueous films that contain cations and organic materials (Brindley and Pedro 1972). This particular structure of montmorillonite is mainly responsible for the expansion of montmorillonite in the presence of water. Clay swelling has been an active area of research since the 1950s. Clay swelling has significant impacts in drilling and production engineering, including wellbore instability and formation damage. It has been suggested that the silicate structure has a permanent negative charge due to the replacement of $\mathrm{Si}^{4+}$ by $\mathrm{Al}^{3+}$ or $\mathrm{Al}^{3+}$ by $\mathrm{Mg}^{2+}$. These exchangeable cations are situated between the silicate layers, neutralizing their charge. The mechanism of clay swelling was described as water molecules entering interlayer positions to hydrate ions present in that region by Norrish (1954). The interlayer spacing increases from $9.5 \mathrm{~A}$, for the dry material, to $20 \mathrm{~A}$, corresponding to four layers of water in crystalline swelling. In the second region of swelling, osmotic swelling, Na-montmorillonite takes up 10-g $\mathrm{H}_{2} \mathrm{O} / \mathrm{g}$ clay and increases its volume by about 20 times. At greater water content, the montmorillonite becomes a thixotropic gel, followed by a sol, and this may be regarded as the third stage of water uptake. Na-montmorillonite in contact with water has been reported as taking up to $10-\mathrm{g} \mathrm{H}_{2} \mathrm{O} / \mathrm{g}$ clay, and this may represent the maximum water content $d \sim 300$ A of normal swelling (Luckham and Rossi 1999). The mechanisms and kinetics of clay swelling in petroleum-bearing formations were discussed in detail by Civan (2007).

While the mechanisms for clay swelling have been extensively studied, there is a very little work published on the interaction of nanoparticles with clays and the mechanisms are not well understood. The purpose of this study is to evaluate the adsorption of surface-modified silica nanoparticles on clay minerals. Understanding the adsorption is a key for subsurface application of nanoparticles, i.e., clay swelling inhibitors, tracers, or fines migration stabilizers.

This work aims to characterize the influence of surface modification with sulfonate, polyethylene (PEG), or quat/ PEG on the adsorption of silica nanoparticles onto clay minerals under moderate conditions to be encountered in subsurface environments, i.e., $25-50{ }^{\circ} \mathrm{C}$ temperature, injected fluid with pH 7-10 and 15,000-30,000 ppm TDS for the applications listed above. We attempt to relate our previous work on the effect of silica nanoparticles on clay swelling with adsorption (Pham and Nguyen 2014). In this study, the adsorption of silica nanoparticles onto montmorillonite and illite surfaces were measured for different nanoparticle surface properties. Adsorption isotherm curves were generated from UV-Vis absorbance readings by determining the difference between initial and equilibrium nanoparticle concentrations. The effects of particle size, electrolyte type $(\mathrm{NaCl}, \mathrm{KCl})$ and concentration, nanoparticle concentration, $\mathrm{pH}$, and temperature on adsorption at the clay surfaces were also evaluated.

\section{Background}

Adsorption of organic compounds on several clay minerals has been widely studied to explore the potential application of clays in industrial wastewater treatment. Parfitt and Greenland (1970) studied the adsorption of polyethylene glycols (PEGs) of varying molecular weights on clay minerals, and they observed that the affinities of polyethylene glycols to the clay surface increased with molecular weights between 200 and 20,000. The authors suggest that the primary contribution to the adsorption energy comes from the entropy gain associated with the desorption of several water molecules for each polymer molecule adsorbed. Zhao et al. (1989) also studied the adsorption of PEG onto montmorillonite clays, arguing that the work by Parfitt and Greenland (1970) primarily used PEG of low molecular weight in impractically high concentrations. They used six different molecular weight PEGs ranging from 300 to 200,000 to study the adsorption, adsorption rate, influence of $\mathrm{pH}$, and influence of different clay types. Rapid adsorption of the PEG for all montmorillonite clays was observed, and equilibrium was reported to be attained within $30 \mathrm{~min}$. The adsorption isotherms for all PEG onto the montmorillonite clays were found to conform to the Freundlich isotherm. Note that the Fruendlich isotherm assumes that the adsorbent is composed of a heterogenous adsorption sites with different adsorption potentials (Zhao et al. 1989).There is no saturation of the adsorbent surface, and the adsorbed amount increases indefinitely with increasing adsorbate concentration (Praus et al. 2008). Parfitt and Greenland (1970) also proposed that the primary adsorption force was the Van der Waals force, since the adsorption heats of PEG on the montmorillonite clays were small. Billingham et al. (1997) studied the adsorption of several water soluble polymers on montmorillonite. Using X-ray diffraction (XRD), PEG was observed to stack as either one or two layers between the clay lamellae as compared to polyacrylic acid (PAA) and polyamine (FL15) which were restricted to a single layer. 
Table 1 Zeta potentials of silica nanoparticles for different surface types

\begin{tabular}{lcl}
\hline Surface modification & Zeta potential $(\mathrm{mV})$ & $\begin{array}{l}\text { Particle diameter } \\
(\mathrm{nm})\end{array}$ \\
\hline PEG & -24.1 & 5 \\
Sulfonate & -31.3 & 5 \\
Quat/PEG & 9.3 & 5 \\
Unmodified & -48.7 & 5 \\
\hline
\end{tabular}

Several studies have focused on investigating the adsorption of nanoparticles at mineral surfaces. However, there is great variation between studies with regard to nanoparticle type and experimental parameters. A study by Antelmi and Spalla (1999) focused on the adsorption of nanolatex particles to flat sapphire $\left(\alpha-\mathrm{Al}_{2} \mathrm{O}_{3}\right)$ and cerium oxide surfaces $\left(\mathrm{CeO}_{2}\right)$. The adsorption density for the nanolatex dispersions was highest at low $\mathrm{pH}$ and decreased as the $\mathrm{pH}$ increased. The adsorption density was found to be strongly influenced by the surface charge of both the nanolatex particles and mineral surface in addition to ionic strength. Adsorption did not occur above the point of zero charge (PZC) for cerium oxide, while a significant adsorption occurred for sapphire above its PZC. The mechanism of adsorption was concluded to be kinetically controlled and different for sapphire and cerium oxide. Metin et al. (2012) studied the adsorption of both unmodified and surface functionalized (PEG- or sulfonate-modified) silica nanoparticles onto calcite and quartz surfaces. The results suggest that adsorption did not occur between both unmodified and surface functionalized nanoparticles with the minerals studied. Yu et al. (2012) conducted a study on the adsorption and transportation behavior of silica nanoparticles in three different porous media: sandstone, limestone, and dolomite. Small amounts of nanoparticles were observed to adsorb onto the sandstone and limestone cores, while no adsorption was observed for dolomite.

\section{Materials and methods}

The montmorillonite and illite clay was purchased from Ward's Natural Science Establishment, Inc., and dry sieved through 400-200 mesh sieves to obtain particle sizes between 38 and $74 \mu \mathrm{m}$, respectively. The clays were then dried at $110{ }^{\circ} \mathrm{C}$ overnight and stored in a desiccator jar prior to use. No further purification of the clay was performed. The silica particles were provided by $3 \mathrm{M}$ (St. Paul, MN, USA). Table 1 shows the diameters, surface coating materials, and zeta potentials of these nanoparticles of $5-\mathrm{nm}$ diameter. Note that quat/PEG is referred to a mixture of quaternary ammonium and PEG used to modify silica nanoparticle surfaces.
The batch adsorption experiments were prepared by adding $0.05 \mathrm{~g}$ of the clay to each of the glass vials that contained $3 \mathrm{ml}$ of aqueous silica nanoparticle dispersion. The vials were then left undisturbed for 10 days to allow for equilibration at $25{ }^{\circ} \mathrm{C}$. A Cary 50 ultraviolet-visible spectrophotometer was used to determine silica nanoparticle concentration in the supernatants via UV-Vis absorbance at $300 \mathrm{~nm}$ and calibration curve. Note that the calibration curve was constructed using the same wavelength, and that $\mathrm{NaCl}$ and $\mathrm{KCl}$ solutions were also confirmed to lack absorbance readings in the ultraviolet regions studied. The adsorption isotherms were generated using the following equation to determine the adsorbed amounts, $a$ (g silica nanoparticles/g clay):

$a=0.01\left(c_{i}-c_{e}\right) M \times m^{-1}$

where $c_{\mathrm{i}}-c_{\mathrm{e}}$ represents the difference in initial and equilibrium nanoparticle concentrations (wt $\%$ ); $M$ is the mass of the nanoparticle dispersion; and $m$ is the mass of the clay (adsorbent).

\section{Results and discussion}

\section{Effect of surface modification}

The adsorption of 5-nm silica nanoparticles on montmorillonite was found to be insignificant at $1.5 \mathrm{wt} \% \mathrm{NaCl}$ and $25^{\circ} \mathrm{C}$ for both unmodified and sulfonate surfaces. However, PEG- or quat/PEG-modified nanoparticles showed significant adsorption and similar isotherms as shown in Fig. 1. In particular, the adsorbed amounts of nanoparticles onto the clay surfaces did not display saturation under the conditions studied. Anderson et al. (2010) showed that cationic quaternary groups might form electrostatic interactions with negatively charged surfaces of the clay, in

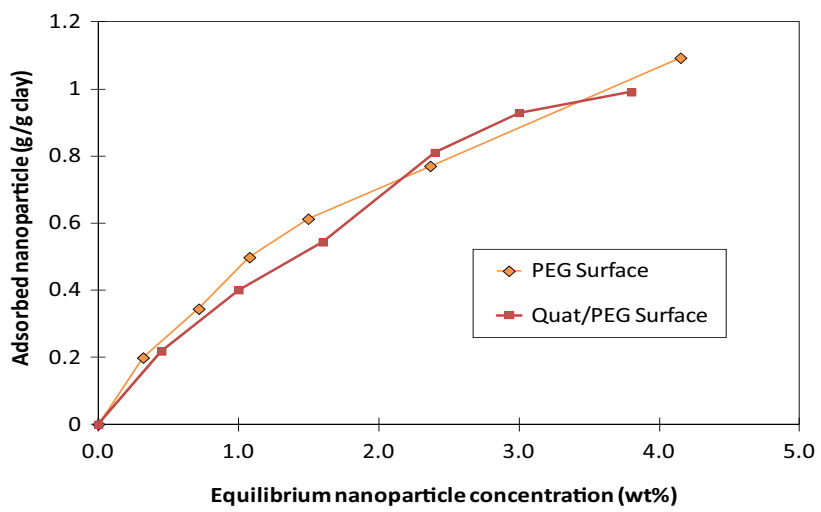

Fig. 1 Respective adsorption isotherms for PEG- and quat/PEGmodified silica nanoparticles on clay at $1.5 \mathrm{wt} \% \mathrm{NaCl}$ solution 
addition to the hydrogen bonds and enhanced inhibition of swelling. Although the surface charge of quat/PEG-coated silica nanoparticles is positive (i.e., positive zeta potential for this surface shown in Table 1), the adsorption results indicate that the presence of quaternary ammonium on silica particle surfaces does not remarkably influence the adsorption isotherm over a wide range of particle concentration.

The adsorption characteristics of PEG-coated nanoparticles shown in Fig. 1 is quite similar to PEG adsorption on montmorillonite. Burchill et al. (1983) demonstrated through neutron scattering studies that hydrophilic polymers, such as PEG, were able to displace the non-coordinated water and bind to the silicate surface as well as to the exchangeable cations through water bridge mechanism. There is a net gain in entropy which provides the driving force for PEG adsorption (Theng 2012). The adsorption of PEG onto montmorillonite gave Langmuir type isotherms and the adsorbed amount increased with the molecular weight. Cliffe et al. (1995) showed that the adsorption of PEG onto montmorillonite gave Langmuir type isotherms without reaching a plateau. Plank (2012) suggested that PEG intercalated with montmorillonite and shifted the d-spacing from $1.23 \mathrm{~nm}$ to $1.77 \mathrm{~nm}$. In addition, it was shown that PEG-2000 could generate highly ordered layer structures by intercalating in between clay layers.

\section{Effect of electrolyte type and concentration}

Figure 2 presents the adsorption isotherms of silica nanoparticles at equilibrium concentrations in the presence of $1.5-3 \mathrm{wt} \% \mathrm{NaCl}$ background concentrations. Up to 1 $\mathrm{wt} \%$ nanoparticle concentrations, there is no significant difference in adsorption between 1.5 and $3 \mathrm{wt} \% \mathrm{NaCl}$. Exceeding this nanoparticle, concentration yields noticeably lower adsorbed amounts for $3 \mathrm{wt} \% \mathrm{NaCl}$ adsorption isotherm. A recent study by Metin et al. (2011) has demonstrated that the PEG-coated silica nanoparticle dispersion remains stable at $\mathrm{NaCl}$ concentrations up to 10 $\mathrm{wt} \%$, suggesting that the observed decreased adsorption at a higher $\mathrm{NaCl}$ concentration is unlikely due to homo-aggregation of the nanoparticles.

Figure 3 shows that adsorption isotherm for $\mathrm{KCl}$ is lower compared to $\mathrm{NaCl}$ at the same concentration for all equilibrium nanoparticle concentrations. Increasing the concentration of $\mathrm{KCl}$ up to $2 \mathrm{wt} \%$ did not significantly modify the adsorption isotherm. The adsorbed amount appears to be dependent on the magnitude of clay swelling influenced by the concentration and type of electrolyte at $25{ }^{\circ} \mathrm{C}$. As electrolyte concentration increases, the magnitude of clay swelling is reduced in visual observation studies. The crystal lattice of the clay is able to exchange cations within a solution to neutralize the charge deficiency

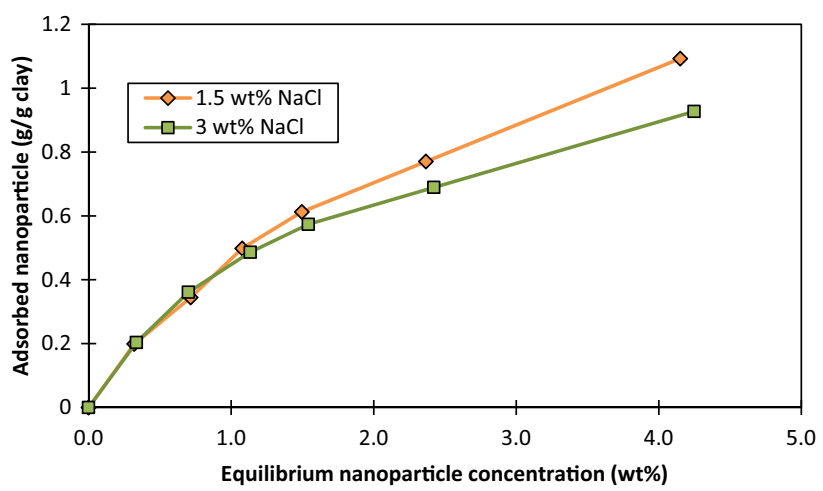

Fig. 2 Isotherms for the adsorption of PEG-modified nanoparticles on montmorillonite at 1.5 and $3 \mathrm{wt} \% \mathrm{NaCl}$ concentrations at $25{ }^{\circ} \mathrm{C}$

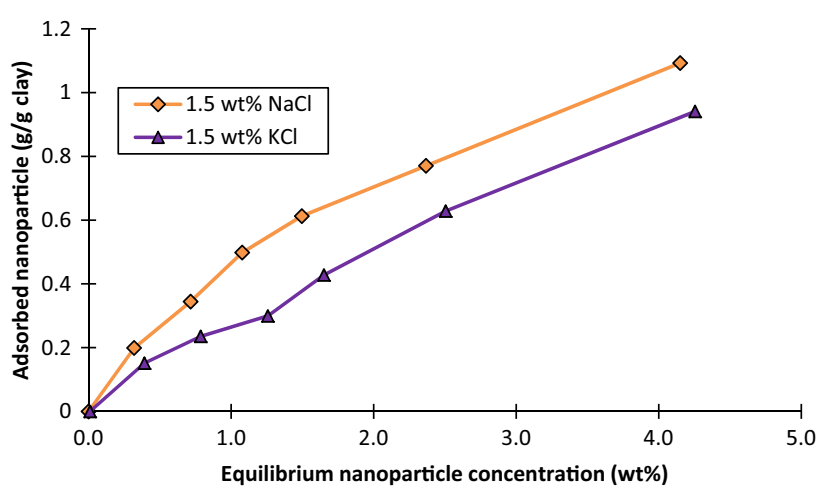

Fig. 3 Isotherms for the adsorption of PEG-modified nanoparticles on montmorillonite at $1.5 \mathrm{wt} \% \mathrm{NaCl}$ and $1.5 \mathrm{wt} \% \mathrm{KCl}$ concentrations at $25{ }^{\circ} \mathrm{C}$

of the clay, influencing the degree of clay swelling. $\mathrm{KCl}$ is known to decrease the magnitude of clay swelling. The ionic radius of the $\mathrm{K}^{+}$cation approximates the hexagonal holes in the silica sheet of the clay, and is able to situate within the cavity. The immobilized $\mathrm{K}^{+}$cations on either side of the interlayer space are able to share a water molecule in this region and reduce clay swelling (Holtz and Kovacs 1981). Moreover, the direct interaction (i.e., iondipole interactions) between the exchangeable cations and PEG molecules may not be responsible for adsorption (Parfitt and Greenland 1970). Instead, it was proposed that the cations retained their hydration shell and that weak bonds were involved between the primary hydration shell of the exchangeable cation and that of the ether oxygen atoms of the polymer to give a water bridge. Liu et al. (2004) observed that the more hydrophobic units there were in the polyglycols, the stronger the adsorption was on montmorillonite layers. Water was displaced from clay and complexes are formed in the presence of $\mathrm{K}^{+}$. Upon addition of $\mathrm{K}^{+}$, the PEO hydration was significantly perturbed and PEO-water pair interaction energy drastically decreased. 
Zhao et al. (1989) studied the adsorption of aqueous PEG on montmorillonite-Na and bentonite II-Ca clays. There was a significant difference in adsorption rates between the two clays, and the observation was attributed to differences between the swelling and dispersion mechanism of the two clays. The electrostatic attraction between crystal layers in montmorillonite- $\mathrm{Na}$ is weaker in the presence of water than bentonite II-Ca, which allows montmorillonite-Na to divide its crystal layers into fine colloidal particles. However, the adsorbed amounts were greater in bentonite II-Ca as compared to montmorillonite$\mathrm{Na}$, which is likely due to differences in the hydrophilicity between the clay surfaces. The results in Figs. 1, 2, and 3 suggest that hydrophilicity is not the primary influence for the difference in adsorption, since the clay types are the same across the samples. The higher slope of the initial portion of the curve suggests that binding occurs more readily at lower nanoparticle concentrations and becomes increasingly difficult at higher nanoparticle concentrations. The relationship between adsorption and spacing of the interlayer region between crystal layers due to electrolyte type and concentrations may indicate a restriction on the ability of the nanoparticle to enter the interlayer region.

\section{Effect of pH}

Figure 4 shows no significant difference between the adsorption isotherms at $\mathrm{pH} \mathrm{7-10.} \mathrm{The} \mathrm{zeta} \mathrm{potential} \mathrm{mea-}$ surements on montmorillonite suspensions showed around $5-\mathrm{mV}$ variation in the range of $\mathrm{pH} 7-10$ as reported by Plank (2012) which may explain the similarity in adsorption behavior at these $\mathrm{pH}$ values. Zhao et al. (1989) investigated the adsorption rates and capacities of PEG onto several montmorillonite clays and observed that there was a little difference in adsorbed amounts of PEG between $\mathrm{pH} 5$ and 12 for montmorillonite. For silicate clays, such as montmorillonite, the permanent negative

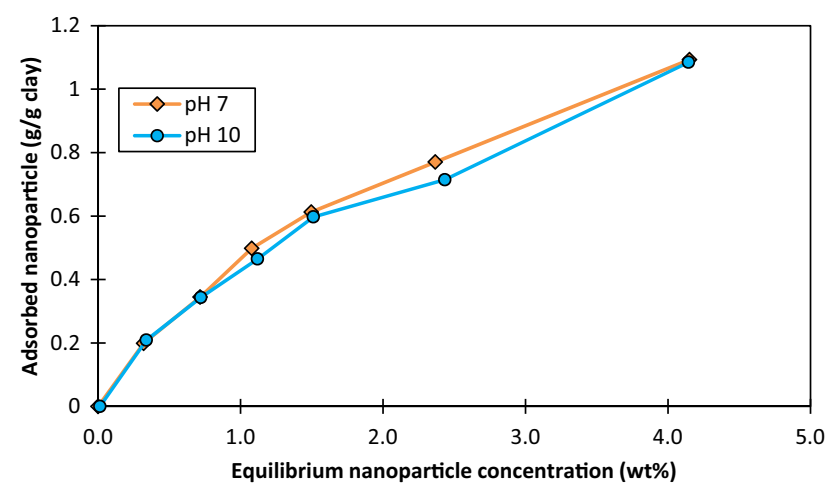

Fig. 4 Isotherms for the adsorption of PEG-modified nanoparticles on montmorillonite at $\mathrm{pH} 7$ and $\mathrm{pH} 10$ in the presence of $1.5 \mathrm{wt} \%$ $\mathrm{NaCl}$ at $25{ }^{\circ} \mathrm{C}$ surface charge is mainly due to isomorphous substitution and is independent of pH (Missana and Adell 2000; Zhou et al. 2012). In a separate study, we did not find any significant differences between the magnitude of clay swelling through visual observations at $\mathrm{pH} 7-10$.

\section{Effect of temperature}

As shown in Fig. 5, the adsorption is significantly decreased at $50{ }^{\circ} \mathrm{C}$ compared to $25{ }^{\circ} \mathrm{C}$. The isotherm at $50{ }^{\circ} \mathrm{C}$ appears relatively linear compared to $25^{\circ} \mathrm{C}$. Although there was a small increase in clay swelling, likely due to increased Brownian motion and kinetic energy of the system, there was a decrease in nanoparticle adsorption. The adsorption for nonionic surfactants will generally increase as the temperature increases due to an inverse temperature-solubility relationship in aqueous solutions (Myers 2006). The decreased adsorption at $50{ }^{\circ} \mathrm{C}$ may indicate that the nanoparticles begin to aggregate, leading to increased effective particle diameters that alter their adsorption ability onto the montmorillonite surface. The results by Metin et al. (2011) indicate that the aqueous stability of PEG-modified silica nanoparticles is affected by increased temperatures. Above a certain salt concentration, known as the critical salt concentration (CSC), the nanoparticle dispersion displays decreased stability. The CSC was observed to decrease as the temperature increased, resulting in increased effective particle diameters and nanoparticle aggregation at elevated temperatures (2 wt $\% \mathrm{NaCl}$ at $70{ }^{\circ} \mathrm{C}$ for PEG-modified nanoparticles) (Metin 2012). The aggregation of nanoparticles at $50{ }^{\circ} \mathrm{C}$ is not significant; therefore, the change in optical density of the dispersion is mainly due to nanoparticle adsorption onto clay mineral. However, an onset of aggregation may affect the concentration measurements.

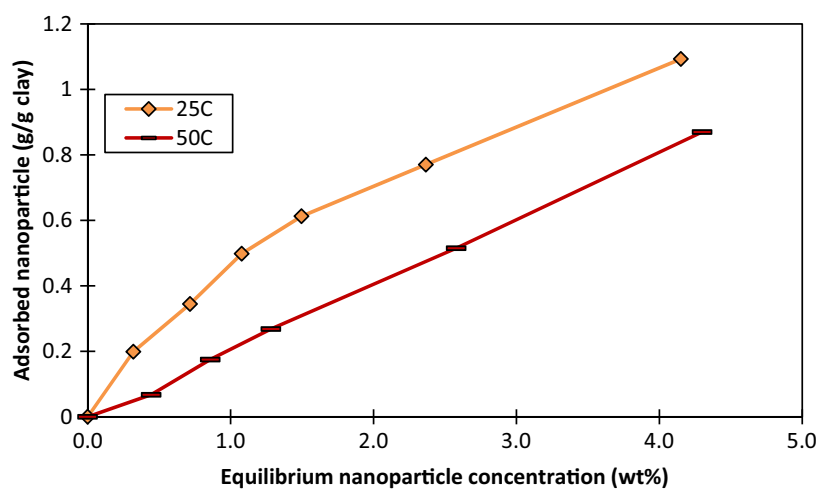

Fig. 5 Isotherms for the adsorption of PEG-modified nanoparticles on montmorillonite at in the presence of $1.5 \mathrm{wt} \% \mathrm{NaCl}$ at 25 and $50{ }^{\circ} \mathrm{C}$ 


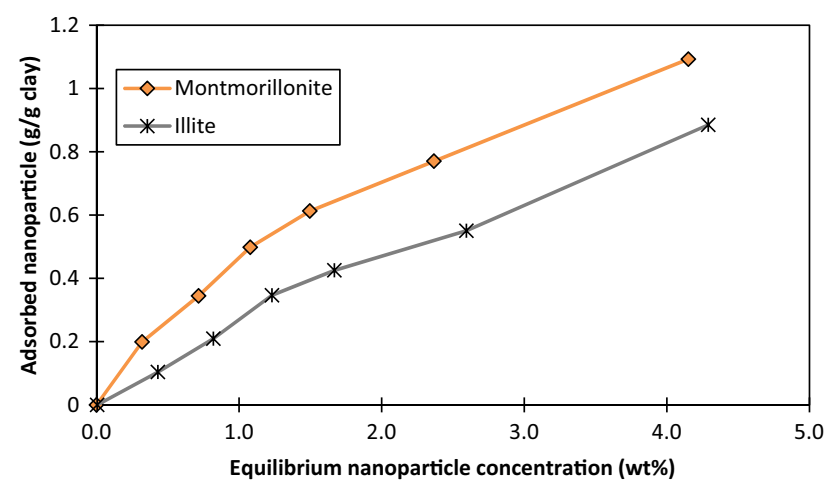

Fig. 6 Isotherms for the adsorption of PEG-modified nanoparticles on montmorillonite and illite at in the presence of $1.5 \mathrm{wt} \% \mathrm{NaCl}$ at $25{ }^{\circ} \mathrm{C}$

\section{Effect of clay type}

The adsorption isotherm of nanoparticles onto illite is presented in Fig. 6. The adsorption of nanoparticles onto illite is much lower compared to montmorillonite. It is not surprising that adsorption occurred, since illite has a crystal structure layering pattern similar to montmorillonite, except the interlayer sheets are held together by a potassium atom. Compared to montmorillonite, illite is considered a non-swelling clay due to the presence of $\mathrm{K}_{+}$cations in the hexagonal holes in the silica sheet which strongly bonds the layers together (Holtz and Kovacs 1981). The decreased spacing of the interlayer region limits movement and entry of the nanoparticles into the interlayer region in much the same way $\mathrm{KCl}$ acts on montmorillonite to decrease nanoparticle adsorption.

\section{Conclusions}

PEG and quat/PEG-modified nanoparticles adsorbed significantly on montmorillonite. Saturation of nanoparticle adsorption was not observed within the ranges of nanoparticle concentration studied, although the adsorption isotherm curves suggest increased difficulty in binding as nanoparticle concentration increased.

Nanoparticle adsorption was found to be influenced by the availability of clay surface area for binding, and a relationship between the magnitude of clay swelling and adsorbed amounts of nanoparticles was observed. The presence of electrolytes, such as $\mathrm{NaCl}$ and $\mathrm{KCl}$ is known to reduce the spacing between the interlayer sheets. $\mathrm{As} \mathrm{NaCl}$ concentration increased, a reduction in nanoparticle adsorption was observed. $\mathrm{KCl}$ is known to reduce the interlayer spacing and swelling more than $\mathrm{NaCl}$, and our results demonstrate decreased nanoparticle adsorption in the presence of $\mathrm{KCl}$.
There was no significant difference in nanoparticle adsorption when the $\mathrm{pH}$ was increased from 7 to 10 . The adsorption isotherm for temperature at $50{ }^{\circ} \mathrm{C}$ displayed significantly lowered adsorption as compared to $25^{\circ} \mathrm{C}$. This difference may be due to a reduction in nanoparticle stability which can alter binding due to increased effective particle diameters. Increased temperatures allow for greater average kinetic energy and particle collisions within the system.

Adsorption isotherms for illite indicate a significant decrease in adsorption. The non-swelling nature of the clay and presence of potassium atoms in the interlayer sheets is thought to restrict nanoparticle movement into the interlayer region, similar to the ability of $\mathrm{KCl}$ to reduce the interlayer spacing in montmorillonite.

Acknowledgments This work was supported by Advanced Energy Consortium at The University of Texas at Austin and the Foundation CMG.

\section{Compliance with ethical standards}

Conflict of interest The author reports no conflicts of interest in this work.

Open Access This article is distributed under the terms of the Creative Commons Attribution 4.0 International License (http:// creativecommons.org/licenses/by/4.0/), which permits unrestricted use, distribution, and reproduction in any medium, provided you give appropriate credit to the original author(s) and the source, provide a link to the Creative Commons license, and indicate if changes were made.

\section{References}

Amanullah MD, Al-Tahini SM Nano-technology-its significance in smart fluid development for oil and gas field application. SPE 126102 presented at SPE Saudi Arab Sect Techn Symp Exhib, Al Khobar, Saudi Arab. 09-11(2009)

Anderson RL, Ratcliffe I, Greenwell HC et al (2010) Clay swellinga challenge in the oilfield. Earth-Sci Rev 98(3-4):201-216

Antelmi DA, Spalla O (1999) Adsorption of nanolatex particles to mineral surfaces of variable surface charge. Langmuir 15:7478-7489

Billingham J, Breen C, Yarwood J (1997) Adsorption of polyamine, polyacrylic acid and polyethylene glycol on montmorillonite: an in situ study using ATR-FTIR. Vib Spectrosc 14:19-34

Brindley GW, Pedro G (1972) Report of the AIPEA nomenclature committee. AIPEA News1 7:8-13

Burchill S, Hall PL, Harrison R et al (1983) Smectite-polymer interactions in aqueous systems. Clay Miner 18:373-397

Cai J, Chenevert ME, Sharma MM, et al (2011) Decreasing water invasion into Atoka shale using nonmodified silica nanoparticles. Paper SPE 146979 presented at SPE Annual Technical Conference and Exhibition. Denver

Civan F (2007) Reservoir formation damage: fundamentals, modeling, assessment and mitigation. Elsevier, Burlington

Cliffe S, Dolan B, Reid P Mechanism of shale inhibition by polyols in water based drilling fluids. SPE 28960 presented at SPE Symp. Oil Field Chem. 14-17 Feb, San Antonio 1995 
El-Diasty AI, Ragab AMS Applications of nanotechnology in the oil \& gas industry: late worldwide and future challenges in Egypt. SPE 164716 presented North Afr Tech Conf Exhib, Cairo, Egypt.15-17 (2013)

Holtz RD, Kovacs WD (1981) An introduction to geotechnical engineering. Prentice-Hall, Englewood Cliffs, pp 77-108

Krishnamoorti R (2006) Extracting the benefits of nanotechnology for the oil industry. J Pet Technol Online 58:24-26

Liu S, Mo X, Sun D et al (2004) Swelling inhibition by polyglycols in montmorillonite dispersions. J Dispers Sci Technol 25(1):63-66

Luckham PF, Rossi S (1999) The colloidal and rheological properties of bentonite suspensions. Adv Colloid Interface Sci 82(1-3):43-92

Metin CO, Lake LW, Miranda CT (2011) Stability of aqueous silica nanoparticle dispersions. J Nanopart Res 12:839-850

Metin CO, Baran JR, Nguyen QP (2012) Adsorption of surface functionalized silica nanoparticles onto mineral surfaces and decane/water interface. J Nanopart Res 14:1246

Metin C.(2012) Characterization of nanoparticle transport in flow through permeable media. Ph. D. Dissertation, The University of Texas at Austin May

Missana T, Adell A (2000) On the applicability of DLVO theory to the prediction of clay colloids stability. J Colloid Interface Sci 230:150-156

Mokhatab S, Fresky MA, Islam MR (2006) Applications of nanotechnology in oil and gas E \& P. J Pet Technol Online 58:4

Myers D (2006) Surfactant science and technology, 3rd edn. John Wiley \& Sons Inc, Hoboken, pp 323-369
Norrish K (1954) The swelling of montmorillonite. Discuss Faraday Soc 18:120-134

Parfitt RL, Greenland DJ (1970) The adsorption of poly (ethylene glycols) on clay minerals. Clay Miner 8:305-315

Pham H, Nguyen QP (2014) Effect of silica nanoparticles on clay swelling and aqueous stability of nanoparticle dispersions. J Nanopart Res 16:2137

Plank J (2012) Interaction mechanisms between Na montmorillonite clay and MPEG-based polycarboxylate superplasticizers. Cem Concrete Res 42:846-854

Praus P, Turicova M, Valaskova M (2008) Study of silver adsorption on montmorillonite. J Braz Chem Soc 19:549-556

Sensoy T, Chenevert ME, Sharma MM Minimizing water invasion in shale using nanoparticles. SPE 124429 presented at SPE Annu Tech Conf Exhib. New Orleans, Louisiana, USA, 4-7 (2009)

Theng BKG (2012) Formation and properties of clay-polymer complexes, 2nd edn. Elsevier, Amsterdam

$\mathrm{Yu}$ J, An C, Mo D, et al Study of adsorption and transportation behavior of nanoparticles in three different porous media. SPE 153337 presented Eighteenth SPE Improv Oil Recovery Symp. Tulsa, Oklahoma, USA, 14-18 (2012)April

Zhao X, Urano K, Ogasawara S (1989) Adsorption of polyethylene glycol from aqueous solution on montmorillonite clays. Colloid Polym Sci 267:899-906

Zhou D, Abdel-Fattah AI, Keller AA (2012) Clay particles destabilize engineered nanoparticles in aqueous environments. Env Sci Technol 46:7520-7526 